\title{
Research of Landscape architecture design situation and development trend
}

\author{
Liang HU \\ Department of logistics management \\ Jiujiang University \\ Jiujiang,Jiangxi,332005 China
}

\begin{abstract}
Landscape architecture is a unique building ; it not only has to meet building functional requirements,but also need to meet the landscape.Therefore,in the design,it should be sure to emphasize the building "put the environment into the scene",no matter is conception,site selection ,spatial layout,or body mass,color,texture and shape,all should be decided on environment conditions, and coordinate building artificial beauty and natural beauty of the environment,only in this way to make the features of the landscape architecture can be brought into full play,then become landscape architecture with the artistic beauty, and thus create an environment that can be home for visitors living walking,touring and appreciating, make garden construction development in a healthy and rapid speed.
\end{abstract}

Keywords- Landscape architecture design situation .Garden. Functional classification

\section{INTRODUCTIONS}

Modern landscape architecture is an important part of the modern landscape, it plays a significant role in enrich urban landscape,as well as to meet the demand of the people of recreational space.Therefore, the design of landscape architecture need to consider the overall planning of the whole park ,the surrounding environment and the characteristics of the boutique itself is flexible layout,in order to achieve the purposes of improving the overall harmony and aesthetic of the garden.

\section{CHINESE GARDEN BUILDING DESIGN FEATURES}

Landscape architecture as one of the four elements of the garden is a unique building,is an important part of our garden .It not only has to meet the functional requirements of the building,but also need to meet the landscaping requirements of the landscape, and blend into natural building.Therefore ,in all cases,it should be appropriate,cleverly combined with function and landscape requirements, unified idea to reflect the different garden environment has distinctive landscape architecture design has the following features;

\section{A. Layout}

The layout of Landscape architecture need to fit in local conditions,need to adroit use of environment for horticulture ,the construction planning and site selection need to consider the functional requirements but also need to make good use of terrain , and combine with the natural environment,then harmony with nature.

\section{B. Scenes lining feeling}

Landscape architecture should be in conjunction with the scenario,express delight, especially in the classical landscape architecture,it often in conjunction with poetry and painting to strengthen the appeal,then reach to scenes lining feeling realm.

\section{Space dealing}

When deal with landscape architecture ,we need to try to avoid the axis into shaping the layout,and strive to twists and turns,scattered mixed,and the spatial arrangement of flexible space is divided to a comparison of the size of the space, it increases the sense of hierarchy,and expand the sense of space.

\section{Shapes}

Architecture is paying more attention to the appearance,the shape of building size,contour must be expressive to increase landscape screen,the body of landscape,building volume and the characteristics of the landscape ,environmental characteristics and local characteristics.In general,in shape of Architecture,the volume should be light,the form should be lively,concise and crisp, and transparent degree thus to achieve the organic unity of function and landscape.

\section{E. Decoration}

When it comes detail decoration,it should be delicate decoration to increase their beautiful,and use to organize the space screen.Decorate them with the commonly used hanging off pictures, the railings, grilles,plaid.

\section{FUNCTIONAL CLASSIFICATION OF LANDSCAPE ARCHITECTURE}

Landscape architecture classified by function mainly is in the following categories;

\section{A. Recreation building}

Use for rest ,tour functions, it has a beautiful shape ,such as kiosks, Gallery,flower,pavilion,boat garden bridges. 


\section{B. Landscape architecture sketch}

Decorate the garden environment as main,pay attention to the appearance of the image of the artistic effect;exhibition card,landscape walls, and railings.

\section{Service building}

Offer life services facilities for tours,such as canteen,tea troom ,snack bar,restaurant,small hotel,and railings.

\section{Cultural and recreational facilities to carry out activities}

Such as the marina game room,club,performance hall,amphitheater,exhibition halls,etc.

\section{E. office management facilities}

It mainly includes the entrance to the park,offices,laboratories,cultivation greenhouse, the zoo and the animal beast chamber.

\section{LANDSCAPE ARCHITECTURE DESIGN METHODS AND TECHNIQUES}

\section{A. Purposive}

Purposive related to the purpose of the design, and is the basic to various composition techniques in the design process."purpose is first , on the tradition of landscape architecture in design not only needs purposive,but also need to learn to grasp the principal contradiction in the design, and can better solve the problem fo building function, but also has a higher realm of art,combining emotion scene,recalling the tragic,scenes lining feeling,which is Chinese traditional gardening features,Another important factor of a landscape architecture Purposive is the environmental conditions, such as green ,water,rocks,terrain, and climate and so on.

\section{B. Eco-design}

Ecological garden is traditional garden development and succession;it follows the design principles of ecology with the construction of multi-function,ulti-structure, multi-level scientific plant communities, then to achieve the perfect combination with artistic beauty and ecological beauty.Ecodesign needs to follow the principles and the principle of unity of the landscape.The principle of landscape architecture is showing the beauty of the plants, reflecting the harmony of art and science.According to the requirements of the people to plant ornamental and aesthetic principle of ecological,need an overall grasp with landscape architecture, has predictability for created plant season landscape and dynamic changes. The principle of unity is both designing to reflect the travel of the opposite sex,but also to enable them to maintain a sense of unity,and around a common subject.The difference is that the type of plant,texture,lines,color and proportion should be some changes and difference.Before the ecological landscape design,first need to conduct site surveys fully grasp the climatic conditions, and then according to the different needs of the Greenbelt to highlight the design characteristics,adhere to economic rationality,suitable for land design and planning of the tree.

\section{Landscape architecture design principles}

The principle of plant based landscaping, architectural design landscaping supplemented.The basic principle of the Chinese gardeners ",landscape is hill,water and plant is first,building is second". In the architectural garden design, the gardens center is building, garden decorative is plants, and garden auxiliary is roads and squares.Therefore, landscape architecture plays a very important role in the garden,plant landscaping should pay a high priority, and garden embellishment of the building need be reasonable.

\section{Landscape coordination of using functions}

Landscape gardening group is determined in the garden construction building size, location,layout,modeling, and other factors, this is the best way to get the best viewing.In Landscape architecture, different types have different principles,coordination of landscape features and the use functional is very important.For Building pavilions,corridors, flower,pavilion, boat,garden bridges these have significantly tour viewing requirements, it should consider landscape features first, supplemented by the principle of using function; as for the garden management, toilet these has a clear right to use function building, it should consider use function-first,supplemented by the principle of landscape functions.

\section{E. Layout in the design of the landscape architecture}

Creation of the landscape architecture needs to scrutinize program organization of the space environment from the overall aspects,so that it can get a good effect on the function and art.The elegant and creative design of the artistic touch,attention should be paid to the organization of the space program in the overall layout.otherwise, the contrast,penetration and levels of artistic treatment mentioned above would be nothing to virtue.

The first characteristic of the spatial sequence is a product combined by sequence is a product combined by sequence of architectural space and the space,viewing freely in each different position and angle,Anglicizing the law of the visitors' activities in design carefully to determine the matter of the space forms and the scenic routes.In a certain route of the visitors' low, the ideal position and angle that can get the best picture must be pre-arranged in order to carry out the intention of the layout.Then,in the processing of building space except the ornamental value,the various properties of different functional requirements must be taken into account in the same time.The spatial sequence of the landscape architecture needs to integrate the artistic conception and function in order to truly achieve good results.

Comparing to imperial palaces and the private houses in the past,our modern landscape is rather different, the requirement of the new gardens is mainly of the plant landscaping is full green. In this aspect,varieties of garden plants applied in our nation,theory and practice of the plant configuration and the management in this area is weaker than those in developed countries,so more attention should be paid to the accumulation of experience on garden 
design,increasing rapidly from the aspects of the practice and theory.

\section{DESIGN OF THE LANDSCAPE ARCHITECTURE SHOULD MEET THE NEEDS OF PEOPLES' SPIRITUAL AND MATERIAL CIVILIZATION}

\section{A. Design of the landscape architecture should achieve the purpose of creating picturesque scenery}

The ultimate goal of the design based on the landscape architecture is to create a picturesque,comfortable, healthy and civilized situation for recreation.Garden is a space art reflecting the social ideology.Garden not only needs to meet the needs of the people' s spiritual civilization, but also is the welfare of society and the reality of real life; therefore,it also needs to meet needs of people' $s$ good rest and material civilization of the entertainment.Its design is firstly based on the scientific principles and technical requirements of the related projects.Secondly,community garden is in the scope of the superstructure to react the social ideology.Thirdly, according to the aesthetic demands,activity patterns and the functional requirements of the masses, the designers of the functional garden create a scenic,hygienic, healthy,comfortable and convenient garden space to meet the visitors' functional requirements of touring,resting and carrying out fitness and entertainment activities.

\section{B. Architecture and conditions of the natural environment}

Environmental protection and energy saving,solar energy,wind energy,how hydropower combined with the building,how to use them, how to achieve environmental protection ecology have been questions that people concern about all the time.The roofs of the Landscape architecture should take the use of solar energy and wind energy into consideration while waterfront building should full consider the use of hydropower.

Modern architecture is a building relying too much on limited energy,energy means life to the buildings with extensive use for artificial lighting and mechanical airconditioning.Building with high consumption of energy and low efficiency is not only an important factor leading to energy shortages but also becomes the culprit of manufacturing the air pollution.Japanese scholars ion concluded that environment pollution,light pollution,electromagnetic pollution and so on.The protection of the ecological environment is the pursuit of green building.

\section{Landscape architecture and nature}

Chinese garden architecture advocates nature, from Lao $\mathrm{Zi}$ and Zhuang $\mathrm{Zi}$ ' s respect for nature to emergence and the development of the landscape poetries,landscape paintings and landscape gardens subjecting to the performance of the natural beauty,they all throughout the philosophical concepts of harmony and unity between man and nature.This concept has a profound impact on the creation of the Chinese garden art,It stresses that laws and gods are all natural and lord is interesting because of the nature,showing the opposition of the done laws and artificial carvings which is contrary to
nature.The most ideal landscape construction is to use the original nature terrain it is gradually formed through millions of years and it has the inherent coordination of the nature so it can save efforts and have rich natural taste But now due to the unlimited reclamation, mining and construction engineering of people,the cities and suburbs has rarely preserved original natural terrain.The situation in China is that,as the largest developing country, China does not allow us constructing garden which cost too much and cover uncontrolled areas in place and city.

\section{Meeting the functional requirements}

The garden is not only a facility to improve and beautify the people' s living environment,but also a venue for people to rest,visit and carry out cultural entertainment.Because of the requirement of a variety of recreation and entertainment activities in the garden, related building should be set up in the garden.With the increasingly rich contents of garden activities, the raising levels of the modern amenities of the landscape as well as the increase in the types of gardens, various types of buildings are bound to appear in the garden to meet the ever-increasing needs of various activities.Not only tea rooms and halls are needed,exhibition halls,performance halls, sporting buildings,constructions of science and technology as well as a variety of activity centers are also involved to meet the functional requirements.

\section{CONDITION AND REFLECTION OF DESIGN OF THE MODERN LANDSCAPE ARCHITECTURE}

As one of the four elements of the garden,landscape architecture often plays the role of integration.However,from an overview of the design of modern landscape,some make slavish mass productions of so-called international landscape architecture and regard foreign exotic products as their own innovations.Others are complacently satisfied with the imitation on the surface or direct copy of the traditional landscape architecture, therefore,we can see that upsurge in today in the construction of gardens, a large number of completely retro gardens have shown up.This attitude towards traditions is not to the mining deep level of the traditional spirits, but to treat simple forms on the surface as a traditions and the understanding of traditions is still in shallow areas of the surface.Over time, it will cause the question of the world:whether the excellent traditional landscape architecture will disappear and whether the characteristics of the nation will flood off,so we are confused then we begin to think that if the rapid spread of the modern landscape will affect the continuation of the traditional landscape architecture and whether traditional landscape architecture still has its vitality in modern time.

\section{A. Problems existing in landscape architecture at this stage}

Overall,the design of the landscape architecture only tends to regard the landscape architecture as a mean of a delineation of space or space complex.Starting from the origin and then discussing the present problems and the reasons. 
For city's landscape architecture at this stage,during the planning and design,designers often take advantage of the form of geometry without feelings, this plan consists of purely abstract shape,in addition to the plan itself,it does not have any real meanings,so if the construction of garden ornaments is according to this design plan,it is destined prone to a failure,At this stage,some complete garden building are mostly not based on the forms in the space or space in the forms.Too much work is piled by geometry,especially in the planning of parks and the cities, the layout is used by simple and boring twodimensional geometry,leading to the irrationality of the three-dimensional geometry,leading to the irrationality of the three-dimensional space and contributing to the better forms and sense of space on the drawings of the landscape architecture stage,however,after construction, it can not achieve the desired results.

\section{CONCLUSIONS}

Landscape architecture is a unique architecture; it not only has to meet the functional requirements of buildings,but also to meet the landscaping needs of the landscape. Therefore, in the design,"scene because of the environment"should be emphasized.Conception, site selection and spatial layout or body mass,color,texture and shape are all depended on environmental conditions. Only coordinating the artificial beauty of architecture and natural beauty of environment can make the function of the landscape architecture plays fully and become the landscape construction with the artistic beauty thus it can create garden environment for visitors to live,wander,visit and view in order to make the garden construction develop rapidly and healthy.

\section{References}

[1] $\mathrm{Hu}$ Gang.Landscape architecture design trends research[J].Science and Technology Information,2009,(13):82.

[2] Liang Haoyan.Talk about the urban landscape architectural design situation and development [J].Science and
Tech Technology,2010,(23);1026

[3] Yan XiangJun.On the status and trends of landscape architecture design[J].Zhong shan University and of Research,2007,(01);139-141.

[4] Wang Tingxi.Development of traditional culture and landscape architecture design[J].Huazhong Architecture, 1994,(01):16-18.

[5] Hu XiaoYi.Research on the development of the architectural design of the city landmark in Shanghai that under the influence of cultural and historical[J].Art and Science,2012,(05):127.

[6] Li Lin.Analysis of green ecological sustainable development point of architectural design[J].Henan Science and Technology,2013,(06):139.

[7] Liu Cai.Landscape architecture design and rotating work Teaching Reform[J].New courses (vocational education),2008,(02):43-45.

[8] Duan Dajuan,Zhang Tao,LI Bingfa.Landscape architecture design Analysis and Improvement Measure [J].Agricultural Research,2000,(S1):67-69.

[9] Kuang Shan.On the urban landscape architecture design[J].Urban Roads Bridges\&Flood Control,2005,(01):4-6. 